\title{
Heterogeneous Class and Teaching Practices within the French Course
}

\section{Anila Pango (PhD Candidate)}

\author{
French Alliance of Tirana, Albania \\ pangoanila@gmail.com
}

\author{
Doi:10.5901/jesr.2015.v5n2p53
}

\begin{abstract}
This study deals with the heterogeneity of classes of French foreign language, the strategies and devices that are suitable to the learning profiles of the public. Learners are different regarding: the learning skills, the way of thinking, their motivation to learn, modes of communication and expression, the socio-cultural environment, culture, beliefs, family history, values, psychological characteristics personality, attention, will, curiosity, energy, rhythm, etc. Individual disparities that show the heterogeneous classes rather appear as a challenge for a "traditional FLE1" teaching. Facing heterogeneous learners, it is essential to implement varied, diversified, cooperative, and comprehensive pedagogy. Differentiated pedagogy, tutoring activities and interaction between students are the methods we have experimented in order to improve the written expression of the students which led us to getting positive results in function of teacher-student interaction. The central idea is that interaction enables students to benefit from the differences by considering them as a source of learning and not as an obstacle.
\end{abstract}

Keywords: heterogeneity, tutoring, group work, writing, evaluation

\section{Introduction}

A heterogeneous public lies behind the word "learner". This explains the reason why we often prefer plural form rather than the singular one, as does the European framework of reference. In fact, a learner who studies a foreign language such as French can be a scholar, a student in college or high school, or an adult. (Robert, J-P., Rosen, E., Reinhard, C. 2011:9) All learners have their own identities and personalities. They speak one or more foreign languages. They possess different levels of knowledge regarding different disciplines and thus have their own individual competencies. They also have their own vision of the world, which is of course defined by their own personal perspectives.

Heterogeneity is inevitable in the groups and classes of a language center. Students who possess different levels of knowledge such as beginner or advanced may be in the same class at the same time. There are also students which have knowledge on the foreign language that they are currently learning, other students who do not know but some vestiges of the language and others who have no prior knowledge about the mentioned language. Apart from this heterogeneity, there is also a coexistence of different groups of students with different ages, tastes, social origins and levels of study within the class. Students in these classes have different communicative needs and goals of learning the language. Some of the students want to get a language certificate (such as DELF / DALF for French), others want to learn a foreign language for specific purposes such as studies, migration etc. This kind of heterogeneity necessarily requires the implementation of specific teaching practices such as differentiated instruction. (Robert, J-P., Rosen, E., Reinhard, C. 2011: 17)

\section{Teaching Practices Versus Heterogeneous Class}

Teaching in heterogeneous classes is a challenging task for teachers. Their behavior towards students in these classes is different. Some teachers treat students in a differentiated way according to their level of competences, by increasing the risk of an emphasis of the disparity between them. They do not ask students to participate the same way, they do not ask the same questions, they do not provide the same support, the same encouragement, do not give the same advices, warnings or praises, but they try to provide them to the students in a differentiated way by meeting the needs of each one of them. Other teachers behave in the same way with all the students, despite their educational and social

${ }^{1}$ Fle - French foreign language 
characteristics. (Mc Kown \& Weinstein, 2008: 235-261)

The heterogeneity of a class should not be a problem for teachers, but on the contrary, they should take advantage of the differences between the pupils to organize the lessons. Differentiated instruction takes into account the peculiarities of each student. This teaching emerged from the students' heterogeneity. According to Perrenoud "the latter has become intolerable for teachers, who, within the limits of reason, can no longer teach as before. Students do not react in a normal way by not allowing teachers to continue the course. Changes between students were so obvious, thus becoming an obstacle to learning and similarities were not strong enough to hide the changes." (Cahiers Pédagogiques, 1997:48)

Differentiated instruction is a method which aims to address heterogeneity. This method involves a different set of tools for teaching and learning to help students progress. It is addressed to all students without distinction, whether they are in difficulty or performing poorly, by seeking to respect the differences and give everyone the opportunity to apply personal strategies. Students, who have different characters, find the solution in plurality: plural rhythms, groups and evaluation forms. Differentiating means to organize interactions and activities, so that each student can constantly face fruitful teaching situations for him. (Perrenoud, 1995:28-29)

Organizations to transform conventional teaching practices which aim the use of the differences between learners as a learning factor are different. Classes can be arranged in groups or pairs, homogeneous or heterogeneous, with the objective of favoring students' aid, interactions, or awareness.

Diagnostic, formative and summative assessments are key levers to implement a differentiated pedagogy; we have few chances to respond the challenge of heterogeneity without them; with differentiated pedagogy everything becomes probable... (Meirieu, 1985:134) So, it is important to recognize knowledge and particularities of competencies of each student, only in this way the appropriate tools of learning situations can be chosen.

We do not claim to be all inclusive in this modest work. We do not pretend to say everything about differentiated pedagogy, but will treat extensively the method of mentoring between pairs of students during cooperative learning. Since our audience is heterogeneous, this method seems to be the most appropriate to us. By mentoring and cooperative learning, we address the pedagogical methods which lead to the transformation of the interactions' structure between students by passing from a structure which is usually competitive or individualistic to a cooperative structure. The central idea is that interaction enables students to benefit from the differences by considering them as a source of learning and not as an obstacle. Tutoring between pairs consists of teaching a student or pupil who is less advanced by a more advanced student (tutor). It should be noted that progress in learning is displayed in the pupil and the tutor as well.

In cooperative learning students work in a small group so that everyone can participate in a collective task which is very well defined. Furthermore, it is assumed that students work without the direct and immediate supervision of teachers. (Cohen, 1994: 3) Working in groups is beneficial in learning. It is characterized by a positive interdependence between members of a group. They need each other to accomplish the task. With this method there also comes a system of individual responsibility which increases possibility to identify the contribution of the members of the group. (Meirieux 1996: 202)

\section{Implementation of Differentiated Instruction in a Heterogeneous Group-Class}

French Alliance of Tirana is a structure for teaching French outside educational institutions. It offers a wide range of high quality courses for each age and level. Based on our teaching experience, with a heterogeneous audience, we will try to talk about the problems we encounter during the teaching process of French and the teaching practices that we implement to achieve our objectives.

The audience consists of adults and young people, for whom learning French is a post-initial education and since this kind of education takes place in a private institution, apart from the statute of students, they also possess the statute of being «clients». They are gathered in the same class according to their level of language, other than that there are numerous differences regarding their motivation and objectives, level of primary education, training and professional field. They are different in terms of acquiring foreign languages also, for some students French is the first foreign language that they are learning, for others it is the second or even the third foreign language.

Consequently, there is a disparity (inequality) in terms of independence and learning strategies.

It is not easy to work with adults. They have facilities such as experience, strong motivation (personal satisfaction, integration, professional ambition) and acquisition of other languages. They also have difficulties such as limited availability. Some adults have lost or haven't had at all the habit of learning like the school learning type.

Like every student, even adults face many difficulties, but their main difficulties are related to the fact that they 
have to make their knowledge concrete when they write in French. This is due to a linguistic competence which hasn't been acquired yet and it is still not automated.

It is undeniable that editing is a very complex process and it is not easy to make students acquire the competence of writing, because writing does not consist solely in the production of a whole-structured language which corresponds to a series of sentences in order to express accurately, but it is all about making concrete of a set of procedures to solve problems. (Cuq, J-P., Gruca, I. 2005:184)

Through our experimentation, we aim to address the issue: how can students who study French improve their competency of writing in a heterogeneous group-class?

We conducted our experiment in the center where we work. We will try to describe some profile features of a student group-class which have been in our charge for 6 hours per week, for a total period of 4 months. Although, the students belong to B2 level, we would like to highlight the fact that similar profiles and scenarios also appear in other classes (such as the levels A1, A2, B1) in which we teach.

There were ten students in the class:

- Four high school students (three girls and a boy). They speak and understand French well. Their purpose of study was the acquisition of B2 level of communicative competence so that they participate in B2 level rehearsals because they wanted to continue their studies in France.

- An Anglophone lawyer whose aim was the acquisition of competence in French in order to read professional literature in French.

- A young woman who had graduated in the Faculty of Medicine, had followed a three-month internship in France and aimed to do another internship in France for which she was required to possess a B2 level certificate.

- A pair of economists, of a certain age, whose objective was of which was the acquisition of oral and writing skills of B2 level to pass the TEF2 testing in order to emigrate in Canada.

- A nurse who wanted to go to Belgium and had many problems with grammar and writing.

- A Spanish student who didn't attend the course regularly and had many problems with writing.

Initially we analyzed the students' needs. Some students needed to improve communication, their speaking skill so that they could transmit a message to their interlocutor, others had linguistic needs. They wanted to improve writing so that they could carry some responsibility such as reading or writing a letter. Regarding the importance of writing and speaking students had different opinions, but most of them paid attention to writing and speaking. Although the students were attending a B2 level course, which meant that they belonged to the average level, the skill of writing seemed a very difficult task to them.

According to the European framework, B2 level is the level of autonomy. At this level the student is able to:

- formulate ideas and arguments clearly.

- organize his argument according to a structured text (in other words, a plan).

- illustrate his way of reasoning with concrete examples (CEFR, 2001:33)

We decided to do a comparative study between written texts which are realized individually and those realized in groups, based on the objectives of our study and to show the efficiency of working in groups or in pairs in writing.

\section{Putting the Experiment into Practice}

A session was devoted to a pre-test, which means that we performed a diagnostic assessment with the students. For this purpose, we proposed a topic taken from the method "Alter Ego 4"(Dollez, C., Pons, S 2007: 19), with which we work currently and students had to write about that topic. The topic was: "Rédigez un article pour la Revue Les Langues Françaises où vous indiquez pourquoi les étudiants étrangers ont besoin de connaitre le français familier des Jeunes et de la rue" (about 200 words).

Criteria for correction:

- The quality of subtitle (chapeau)

- Article Plan

- Respect of the requirement (three reasons and examples)

- Linguistic correctness

An analysis of the written materials made possible the classification of errors in percentage.

2 TEF - The Test d'Évaluation de Français, Canada 
- $40 \%$ of the students have written insufficient texts regarding content or form. Planning is totally neglected by these students who have passed directly to the text. Texts are not coherent. They are not organized into paragraphs and the most used linking words are: et, mais, parce que, etc.

- $20 \%$ of the students have not respected the minimum length required. Regarding linguistic correctness, there are many errors that happen as a result of lexical and grammatical interferences.

- By deepening the analysis on the criterion of age we came to this conclusion. Adult students have mainly lexical errors due to the interferences of their native language or English. Interferences may affect different levels of language organization. (R. Galisson and D. Coste 1976: 291) They often turn to use semantic calques or word for word translations from Albanian to French thus forming sentences like: J'ai un an que j'ai commencé à étudier le français (instead of "Il y a un an que j'ai commencé à étudier le français "= It has been a year since I started studying french ). However, their texts are coherent.

Whereas the texts of younger students have less lexical, syntax or spelling problems and more problems with the organization of arguments and the construction of the text. There are cohesion errors in their texts. Cohesion concerns the ways in which the components of the tekst, i.e. the actual words we hear or see are mutually connected within a sequence. (Beaugrande and Dressler., 1981: 3) So they lack "a very wide range of vocabulary" and do not have "a good grammatical control", competencies which are required in B2 level. (CEFR, 2001:30)

The error of a student is a learning tool for him. This is an important step in learning French not only for the student but for the teacher as well. Errors aren't inexcusable mistakes or flaws for which we feel sorry, but they are symptoms of difficulties which students face. (Astolfi, J-P. 1997: 15)

After correction, we asked students to reflect and answer these questions that relate to writing strategies.

- In what language do you think before you write?

- What do you do before you write?

- What should be done to produce a better text?

- Do use a paper?

- What do you do when you write directly on the paper?

The answers indicate that students have difficulties in writing. Regarding the first question, the students, especially adults, say they use translation in their mind, which leads to errors associated with negative transfers. Most students find out that they do not plan before they write and do not use a paper. There are some students who claim to re-read the text before submitting it to the teacher. These students are used to reviewing the text before submitting it to the teachers, but other students are not.

To improve these flaws and mistakes, we continued with a method based on activities that are logically related to help students have knowledge about the writing process and strategies that should be used to produce a coherent text. The problem that students often face while they are writing is lack of ideas. Like most of the difficulties in writing, even this difficulty is related to the difficulties in reading. Making students acquire the ability of reading and writing is not an easy task. In fact, these skills should be developed in primary and secondary school. We thought to work simultaneously on both competences comprehension and writing.

\section{Writing Strategies}

We programmed a sequence that contains activities based on the editing strategies such as reading, writing, planning, reviewing and self-assessment. We divided the task in three phases so that we could work with the skill of writing.

- The first phase consisted on reading a text, and it was of course an individual reading. For this activity, we used a formal paper model and the class had to analyze it in details. We also started with an attentive reading of the text for all the exercises based on the documents. Then we continued with the usual analysis which comes after each attentive reading of the text. (Who? Whom? What kind of document? What is the text about?); we had received a formal letter, which was easily identifiable by its appearance, from which we took some details in the class (the sender's name on the left, the recipient's on the right, date, opening and closing statements, signature).

- The second phase of the work was conducted in pairs. The given task was to find ideas / arguments used by the writer in the extract and the linking words. This stage was a second attempt to understand better a written text and a first test to write in French. We proposed to the students an imitation exercise. They chose an argument from the reading materials. They had to write a paragraph about that argument. We asked them to be careful with the use of the five parts of a good paragraph: 
1. One Main Idea

2. Topic Sentence

3. 5-7 Sentences

4. Closing Sentence

5. Indent; Spelling and Punctuation

- At the end of the exercise we proposed a cross correction: then we took the copies, and distributed them again to the students who had to correct the copy of another group using the assessment grid:

Table 1.0

\begin{tabular}{|l|l|l|l|}
\hline \multicolumn{1}{|c|}{ Criteria } & $\begin{array}{c}\text { Yes, well } \\
\text { done }\end{array}$ & $\begin{array}{c}\text { OK, needs some } \\
\text { improvement }\end{array}$ & \multicolumn{1}{|c|}{$\begin{array}{c}\text { No, needs } \\
\text { improvement }\end{array}$} \\
\hline The ideas, arguments, examples are in the right order & & & \\
\hline They have avoided repetition & & & \\
\hline $\begin{array}{l}\text { They have used linking words which connect the ideas and } \\
\text { sentences and make the text coherent }\end{array}$ & & & \\
\hline They have concluded their argument using linking words like & & & \\
\hline They have written grammatically correct sentences & & & \\
\hline They have - varied their vocabulary by using synonyms & & & \\
\hline
\end{tabular}

- Third stage: the proposal of the topic. We proposed to the students to deal with a complete written task: "Vous habitez dans une ville française. Vous apprenez que cette ville s'apprête à accueillir la "Semaine des cultures du monde". Écrivez au Directeur du festival pour le convaincre de consacrer une journée à l'art de votre pays d'origine" (about 250 words).

At the beginning of the third stage, we followed some steps, which every teacher of foreign languages bear in mind during teaching the skill of writing: before students start to write they need to understand the task and some advices should be given to them. Before the students start to write, the parameters of production situation should be explained to them. This is the most important stage in the overall strategy of writing. This acquisition should be done carefully and by having a high demand until it becomes automated for each student. We asked students to work in pairs about an argumentative text by highlighting the following points:

1. The first three stages should be respected: general topics (what is it about?), issue (what is the question?), presentation of arguments.

2. To set up a general argumentative plan, arguments accompanied by examples.

3. The number of words should be taken into account ( 250 words)

Based on the criteria that we had to evaluate in writing, we realized this table;

Table 2.0

\begin{tabular}{|c|c|c|}
\hline \multirow{2}{*}{ Conformity with a formal letter: } & Respects the situation of the kind of production that is required $/ 2$ & \multirow{2}{*}{5 points } \\
\hline & Can adjust production to the situation $/ 3$ & \\
\hline \multirow[b]{2}{*}{ Content } & Can evoke clearly and accurately facts, events or situations $/ 2$ & \multirow[b]{2}{*}{10 points } \\
\hline & $\begin{array}{l}\text { Can develop arguments by emphasizing properly the most important points and details } / 4 \\
\text { Cohesion, clarity and coherence } / 4\end{array}$ & \\
\hline Linguistic competence & $\begin{array}{l}\text { Morpho-syntactic competence and spelling/6 } \\
\text { Lexical competence /4. }\end{array}$ & 10 points \\
\hline
\end{tabular}

\section{Analysis and Comments of Results}

Teaching / learning of writing in a group allows stimulation of linguistic creativity and formation of communicative competence. To show the effectiveness of working in groups to develop the skill of writing, we have conducted a comparative study between writing tasks performed individually and by working in groups.

First we read some writing tasks performed individually by the more skilled good students and we compared them with those tasks accomplished collectively by the same students. Then, we started analyzing the tasks of the entire class which were conducted in groups ( 5 groups), after that we compared them with those which were made individually by 
other students. Our aim was to discover the difficulties and achievements of the students.

By comparing the tasks which were made collectively with those performed individually by the same students, we came to the conclusion that students who had a very good level of French had done a better job in the group.

- $\quad$ The edited text contains less mistakes and difficulties.

- They are oriented towards building complex sentences.

- $\quad$ The text is coherent, well-built and divided into paragraphs.

Regarding all tasks, we can say that the texts have a good structure and are organized into the three main parts, the introduction part, body and conclusions.

- For this aim, the textual structure has been respected; logic linking words are used at the beginning of each part.

- $\quad$ A wide range of vocabulary is used and adapted to write the type of text (argumentative text).

While the texts written individually, displays difficulties and weakness regarding semantic and morphosyntactic features. Students frequently use simple sentences.

We wanted to know the students' opinions and that is the reason why we conducted a questionnaire at the end of the experiment. In this questionnaire, more points were mentioned such as: communication within the group, the interest of the work in the level of acquiring the competence of writing. They responded that thanks to the work in groups, it was possible to compare the way through which they understand things and gain confidence in themselves. They express freely even if shy, express a critical opinion, ask questions and exchange ideas. We can say that class separation in heterogeneous groups based on the existence of differences between the presentations of students, however not very distant from each other, favors the exchanges between them. Conclusion: by having conversations with each other and by comparing their views students start to learn, including those who have more difficulties.

There isn't only one way to implement differentiated pedagogy. Undoubtedly, it belongs to the teachers to build a teaching strategy that allows all students to achieve the same objectives in different ways while respecting the needs of students.

\section{Conclusions}

Heterogeneity is a reality faced by every teacher. Even if students are grouped in the same class, they are different in terms of knowledge, personality and personal culture. Differentiated pedagogy is a tool which respects these differences to the extent that it consists in multiplying learning itineraries. It is spontaneous and can be performed daily. Teachers are aware of the fact that their style of teaching does not have the same impact on all students and are able to differentiate teaching practices according to the students.

By comparing the individual and collective written tasks of the students, we can say that working in pairs is always better and more fruitful than individual work. Analysis of the products of the students also told us that during the activities in a small group, new competencies emerge, students are not shy anymore. They can interact, agree, disagree, interrupt, present an opinion, and ask for clarification or assistance appropriately. (Harper \& de Jong, 2004: 154).

Tutoring, as we saw, enables the individualization and personalization of learning activities of students by favoring their activities. This situation is beneficial for both parties. The first student will be persuaded that he is able and the second sees success as possible and feasible. This method also leads to the reduction of errors. Products in pairs have less linguistic and spelling errors than individual ones. However, the quality of work depends more on the composition of the pair. Therefore, the other groups should be appropriately paired, so that the weak students can benefit from the good students and improve their level.

However there are also some limitations. First, not all students feel good with this method. Moreover, it takes time to form tutors, which means more time should be spent with students who are performing well. There isn't any unique model. Each teacher creates its own model by being inspired by the reality and different experiences in the field.

\section{References}

Astolffi, J-P., (1977). L'erreur, un outil pour enseigner, ESF éditeur, Paris, p.15

Battut, E., Bensimon, D., (2006). Comment différencier la pédagogie, Edition RETZ

Cohen, E. (1994). Le travail de groupe : Stratégies d'enseignement pour la classe hétérogène. Montréal : Editions de la Chenelière, p.3 Crahay, M. (2000). L'école peut-elle être juste et efficace ? De l'égalité des chances à l'égalité des acquis. Bruxelles : De Boeck.

Cuq, J-P., Gruca, I., (2005). Cours de didactique du Français langue étrangère ,2 édition, PUG., p.184

De Beaugrande, R., Dressler, W.U. (1981). Introduction to Text Linguistics. London: Longman. 
De Perretti, A., (1985). Qu'est-ce Que La Pédagogie Différenciée ? Cahiers Pédagogiques, $n^{\circ} 239$

Dollez, C., Pons,S. (2007). Alter ego Méthode de français, Hachette, Paris, p.19

Galant, B. (2009). Hétérogénéité Des Elèves Et Apprentissages : Quelle Place Pour Les Pratiques D'enseignement ? Les cahiers de recherche du GIRSEF, p.71.

Galisson, R. et Coste, D. (1976). Dictionnaire de didactique des langues, Paris : Hachette

Harper, C., \& de Jong, E. (2004). Misconceptions About Teaching English Language Learners. Journal of Adolescent and Adult Literacy, 48 (2), pp. 152-162.

Mahieu, P. (1992), Travailler en équipe, Hachette, Paris.

Mckown, C. \& Weinstein, R.S. (2008). Teacher Expectations, Classroom Context, And The Achievement Gap. Journal of School Psychology, pp.46, 235-261.

Meirieu, P. (1985). L'école, mode d'emploi des méthodes actives à la pédagogie différenciée, ESF., p.134

Meirieu, P. (1996). Apprendre en groupe 1.Itinéraires des pédagogies de groupe, Lyon Chronique Sociale

Milanovic, M. (2001). Common European Framework of References for Laguages: Learning, Teaching, Assessment. Language Examining and Test Development. (Dir). Strasbourg, Language Policy Division, Council of Europe, p.33 [Electronic version]

Perrenoud, P. (1995). La pédagogie à l'école des différences. Paris,ESF., pp.28-29

Perrenoud, P. (1997). Retours Sur La Pédagogie Différenciée, Cahiers Pédagogiques, $n$ ³, Octobre - Novembre 1997, p.48

Przesmycki, H. (1994). Pédagogie différenciée, Hachette.

Robert, J-P., Rosen, E., Reinhard, C. (2011). Faire classe en FLE. Hachette, pp.9-18

Vecchi, G. de. (2000). Aider les élèves à apprendre. Paris : Hachette. 
